\title{
Properties of Retinal Precursor Cells Grown on Vertically Aligned Multiwalled Carbon Nanotubes Generated for the Modification of Retinal Implant-Embedded Microelectrode Arrays
}

\author{
Sandra Johnen, ${ }^{1}$ Frank Meißner, ${ }^{2}$ Mario Krug, ${ }^{2}$ Thomas Baltz, ${ }^{1}$ Ingolf Endler, \\ Wilfried Mokwa, ${ }^{3}$ and Peter Walter ${ }^{1}$ \\ ${ }^{1}$ Department of Ophthalmology, University Hospital RWTH Aachen, Pauwelsstraße 30, 52074 Aachen, Germany \\ ${ }^{2}$ Fraunhofer Institute for Ceramic Technologies and Systems, Winterbergstraße 28, 01277 Dresden, Germany \\ ${ }^{3}$ Institute for Materials in Electrical Engineering 1, RWTH Aachen University, Sommerfeldstraße 24, 52074 Aachen, Germany \\ Correspondence should be addressed to Sandra Johnen; sjohnen@ukaachen.de
}

Received 8 January 2016; Accepted 4 April 2016

Academic Editor: Wai T. Wong

Copyright ( $\odot 2016$ Sandra Johnen et al. This is an open access article distributed under the Creative Commons Attribution License, which permits unrestricted use, distribution, and reproduction in any medium, provided the original work is properly cited.

Background. To analyze the biocompatibility of vertically aligned multiwalled carbon nanotubes (MWCNT), used as nanomodification to optimize the properties of prostheses-embedded microelectrodes that induce electrical stimulation of surviving retinal cells. Methods. MWCNT were synthesized on silicon wafers. Their growth was achieved by iron particles (Fe) or mixtures of ironplatinum (Fe-Pt) and iron-titanium (Fe-Ti) acting as catalysts. Viability, growth, adhesion, and gene expression of L-929 and retinal precursor (R28) cells were analyzed after nondirect and direct contact. Results. Nondirect contact had almost no influence on cell growth, as measured in comparison to reference materials with defined levels of cytotoxicity. Both cell types exhibited good proliferation properties on each MWCNT-coated wafer. Viability ranged from 95.9 to $99.8 \%$, in which better survival was observed for nonfunctionalized MWCNT generated with the Fe-Pt and Fe-Ti catalyst mixtures. R28 cells grown on the MWCNT-coated wafers showed a decreased gene expression associated with neural and glial properties. Expression of the cell cycle-related genes CCNC, MYC, and TP53 was slightly downregulated. Cultivation on plasma-treated MWCNT did not lead to additional changes. Conclusions. All tested MWCNT-covered slices showed good biocompatibility profiles, confirming that this nanotechnology is a promising tool to improve prostheses bearing electrodes which connect with retinal tissue.

\section{Introduction}

In certain diseases of the neural system, the loss of function can be treated by means of electrical stimulation provided by electronic implants. For example, the cochlear implant has developed to a well established auditory prosthesis used to treat children born deaf or adults with profound hearing loss [1]. The electrodes are located on a linear array that is inserted into the cochlea. After stimulation of the distantly located ganglion neurons, signals are transmitted to the cortex and interpreted as auditory perception.

In the visual system, inherited retinal degenerations, such as retinitis pigmentosa (RP), may lead to blindness and are currently not treatable. RP is characterized by a progressive rod-predominant photoreceptor cell death and affects $0.025 \%$ of the population [2]. Its hereditary forms are based on autosomal dominant, autosomal recessive, or Xlinked mutations in a variety of genes that are involved, for example, in ciliary trafficking and phototransduction $[3,4]$. In order to replace the lost visual input usually mediated by photoreceptor-based transduction into the neural network of the retina, implants were developed to induce visual percepts by electrical stimulation of retinal neurons. These systems, usually referred to as retinal implants (RI), consist of an array of small electrodes, which are either implanted into the subretinal space $[5,6]$, the intrascleral space $[7,8]$, or at 
the epiretinal site [9-11], as well as electronic components to generate stimulation pulses and to manage data and energy transfer.

In contrast to the millions of rods and cones in the healthy retina, RI are equipped with a comparatively low number of electrodes $[6,7,9]$. The EPIRET3 prosthesis, designed and fabricated as a remotely controlled wireless device, includes a microelectrode array consisting of 25 electrodes [11]. Further studies, which were based on the EPIRET3 implant, led to the development of a large flexible multielectrode array [12] as well as flexible microelectrode arrays with an integrated CMOS-chip that will be connected via bus system [13]. These improvements, which result in an increased number and density of stimulating electrodes, but also a suitable three-dimensional design of the electrode itself, narrowing its electrical field, would enhance the prostheses' spatial resolution. The design of such an array has to take several aspects into account. In order to achieve a very high number of electrodes in spite of the limited space for implants within the eye, electrodes have to be closely packed together with low spacing in between and a single electrode has to be small in particular geometrical diameter. However, a small electrode surface is accompanied with an increase in current and charge density, leading to impaired properties of the electrode, and to tissue damage as a consequence of electrochemical reactions [14-17]. Thus, high density electrode arrays are needed, consisting of newly designed electrodes with a small geometric diameter but an enlarged surface area in order to improve tissue biocompatibility and cell adhesion. One promising approach that allows for an extended surface area, while keeping the diameter as small as possible, would be the use of vertically aligned MWCNT-coated on the electrode substrate. Functionalized microelectrodes with integrated aligned MWCNT have been demonstrated to provide an enhanced charge injection limit without heterogeneous charge-transfer reactions that can occur at the electrode surface $[18,19]$. Therefore, MWCNT exhibit a promising nanomaterial suitable for neural prostheses. In particular, MWCNT-coated substrates have been shown to support neurite outgrowth, increased neuronal electrical signaling, and synaptic strength [20-22].

In our study, we investigated several vertically aligned MWCNT-coated structures, which differed in the use of distinct $\mathrm{Fe}$ catalysts during synthesis. Since oxygenplasma treatment was described to render the CNT surface hydrophilic [23] and hydrophilic surfaces promote cell growth [24], plasma-treated MWCNT were analyzed in comparison to nonfunctionalized MWCNT. Corresponding to the standard ISO 10993 "biological evaluation of medicinal devices," part 5 (tests for in vitro cytotoxicity) and part 12 (sample preparation and reference materials), biocompatibility was assessed by analyzing the cell growth after direct contact to the vertically aligned MWCNT and after nondirect contact, where the cells were incubated with the respective extractive media. As prescribed by the standard specification, experiments were carried out using L-929 cells, which were reported to be a sensitive cell line [25]. With reference to the surviving cells of the neurosensory retina being the target tissue, growth properties of R28 cells, a retinal precursor cell line that shows both neuronal, and retinal mRNA characteristics [26] were additionally evaluated.

\section{Materials and Methods}

2.1. Cell Culture. L-929 cells (ATCC No. CCL-1) were maintained in minimum essential medium (MEM) with Earle's salts (Biochrom, Berlin, Germany) supplemented with 10\% fetal calf serum (FCS; PAA Laboratories, Pasching, Austria), $2 \mathrm{mM}$ L-glutamine (Biochrom), $80 \mathrm{U} / \mathrm{mL}$ penicillin, and $80 \mu \mathrm{g} / \mathrm{mL}$ streptomycin (Lonza, Basel, Switzerland) at $37^{\circ} \mathrm{C}$ in a humidified atmosphere of $95 \%$ air and $5 \% \mathrm{CO}_{2}$. The retinal precursor cell line R28, developed by immortalization of postnatal day 6 rat retina [27], was maintained in Dulbecco's modified Eagle's medium (DMEM; Biochrom) supplemented with $10 \%$ fetal bovine serum (FBS; PAA Laboratories), $5.5 \mathrm{~mL}$ of 100x MEM vitamins and nonessential amino acids (Biochrom), $80 \mathrm{U} / \mathrm{mL}$ penicillin, and $80 \mu \mathrm{g} / \mathrm{mL}$ streptomycin at $37^{\circ} \mathrm{C}$ in a humidified atmosphere of $95 \%$ air and $5 \% \mathrm{CO}_{2}$. Medium was changed 3 times a week. Cells were passaged once or twice a week at a ratio of $1: 20$.

\subsection{Synthesis of Nonfunctionalized Vertically Aligned} MWCNT. Synthesis was carried out on $8 \times 8 \mathrm{~mm}^{2}$ silicon wafer pieces (Figure 1(a)) by chemical vapor deposition (CVD). Length and homogeneity were improved by an interlayer of $15 \mathrm{~nm} \mathrm{Al}_{2} \mathrm{O}_{3}$. Vertically aligned MWCNT growth was achieved by nanoscale layers of Fe as well as mixtures of Fe-Pt and Fe-Ti (thickness of $3 \mathrm{~nm}$ ) acting as catalysts (Figure 1(b)). Synthesis was carried out at atmospheric pressure and a temperature of $700^{\circ} \mathrm{C}$ using a $3: 1$ gas mixture of hydrogen and acetylene. Argon was used as feeding gas to achieve gas exchange, needed for MWCNT growth. After a deposition time of $20 \mathrm{~min}$, vertically aligned MWCNT with $18 \mu \mathrm{m}$ length and $16 \mathrm{~nm}$ outer diameters were received by synthesis with pure $\mathrm{Fe}$ catalyst. In case of Fe-Pt catalyst, vertical aligned MWCNT with $60 \mu \mathrm{m}$ length and $28 \mathrm{~nm}$ outer diameters were synthesized, whereas $\mathrm{Fe}-\mathrm{Ti}$ catalyst allowed vertical aligned MWCNT production with $85 \mu \mathrm{m}$ length and $9 \mathrm{~nm}$ outer diameters, as characterized by high-resolution transmission electron microscopy (Figure 1(c)). Prior to the use in cell culture, the wafers had to be sterilized by autoclaving at $121^{\circ} \mathrm{C}$ for $30 \mathrm{~min}$, which did not affect the MWCNT coating and structure (Figure 1(d)).

\subsection{Synthesis of Plasma-Treated Vertically Aligned MWCNT.} Synthesis was carried out on $8 \times 8 \mathrm{~mm}^{2}$ silicon wafer pieces by CVD. The interlayer system consisted of undoped silica glass followed by $20 \mathrm{~nm}$ titanium and $40 \mathrm{~nm}$ titanium nitride on top. A mixture of Fe-Pt with a thickness of $3 \mathrm{~nm}$ was used as catalyst. MWCNT synthesis was carried out at atmospheric pressure and a temperature of $620^{\circ} \mathrm{C}$ using a $3: 1$ gas mixture of hydrogen and acetylene with argon as feeding gas. The deposition time of 40 minutes resulted in MWCNT with $8.6 \mu \mathrm{m}$ length. Some of the substrates were plasma-treated using a RF plasma at $13.56 \mathrm{MHz}$ with $0.2 \mathrm{~W} / \mathrm{cm}^{2}$ at a total pressure of 2 mbar with a $1: 1$ gas mixture of oxygen and argon. The treatment time was 30 seconds. Prior to use in 


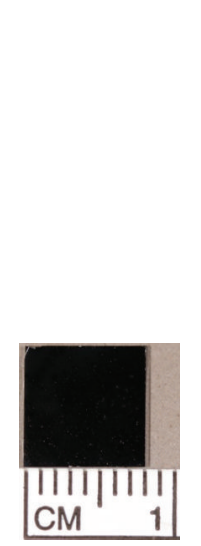

(a)

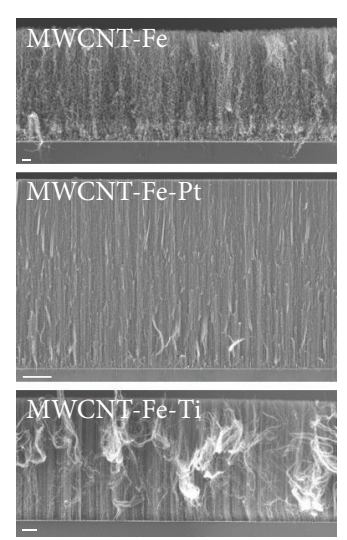

(b)



(c)

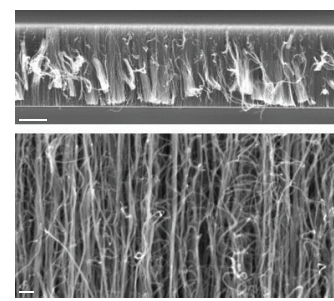

(d)

FIGURE 1: Characterization of vertically aligned MWCNT growth achieved by a nanoscale catalyst layer of Fe, Fe-Pt, and Fe-Ti. (a) Synthesis was carried out on $8 \times 8 \mathrm{~mm}^{2}$ silicon wafer pieces by chemical vapor deposition. (b) Scanning electron microscopy demonstrated the aligned growth of the synthesized MWCNT with a length of $18 \mu \mathrm{m}$ for the Fe catalyst (scale bar: $1 \mu \mathrm{m}$ ), $60 \mu \mathrm{m}$ for the Fe-Pt catalyst (scale bar: $10 \mu \mathrm{m}$ ), and $85 \mu \mathrm{m}$ for the Fe-Ti catalyst (scale bar: $10 \mu \mathrm{m}$ ). (c) High-resolution transmission electron microscopy demonstrated the integrity and consistency of the Fe-Ti catalyzed MWCNT growth with an outer diameter of $9 \mathrm{~nm}$ and an inner diameter of $3 \mathrm{~nm}$ (scale bar: $5 \mathrm{~nm}$ ). (d) Steam sterilization at $121^{\circ} \mathrm{C}$ for 30 minutes showed no impairment (scale bar upper panel: $10 \mu \mathrm{m}$, scale bar lower panel: $100 \mathrm{~nm}$ ).

cell culture, wafers were sterilized by autoclaving at $121^{\circ} \mathrm{C}$ for $30 \mathrm{~min}$, which did not affect the MWCNT coating and structure.

\subsection{Nondirect Contact with MWCNT-Coated Silicon Wafers.} According to the description in part 12 of the standard ISO 10993, the materials were incubated at $37^{\circ} \mathrm{C}$ for $72 \mathrm{~h}$ in a humidified atmosphere of $95 \%$ air and $5 \% \mathrm{CO}_{2}$. To avoid blank surfaces, incubation was carried out in one well of a 4-well Nunc ${ }^{\mathrm{TM}}$ Lab-Tek $^{\mathrm{TM}}$ Chamber Slide System (Thermo Fisher Scientific, Waltham, MA) using $0.5 \mathrm{~mL}$ of cell culture medium, which was declared as the lowest applicable quantity of liquid. Subsequently, the extractive media were collected and directly applied at different dilutions $(1: 1,1: 2$, and $1: 4)$ to precultivated L-929 and R28 cells (seeded at a density of 31,250 cells $/ \mathrm{cm}^{2}$ and incubated at $37^{\circ} \mathrm{C}$ for $24 \mathrm{~h}$ ). Cell densities were chosen with regard to the subsequent assay to give evaluable results. After another 24 hours of incubation at $37^{\circ} \mathrm{C}$, cell viability was assessed using the CellTiter-Glo ${ }^{\circledR}$ Luminescent Cell Viability Assay (Promega, Madison, WI) according to the manufacturer's protocol. The assay is based on quantitation of the adenosine triphosphate, which signals the presence of metabolically active cells. Corresponding to part 12 of the standard ISO 10993, certified positive and negative reference materials (RM; Hatano Research Institute, Hadano, Japan) were used as controls: the positive RM A shows a moderate level of cytotoxicity and consists of a polyurethane film containing $0.1 \%$ zinc diethyldithiocarbamate; RM B contains $0.25 \%$ zinc dibutyldithiocarbamate and exhibits a weaker cytotoxicity; the negative RM C consists of a high density polyethylene film. In addition, medium incubated without any material was prepared (glass). The reference materials were $8 \times 8 \mathrm{~mm}^{2}$ in size, analogous to the MWCNT-coated silicon wafers. Each single sample was measured in triplicate; the resulting mean value was used for further analysis. Data (mean \pm standard deviation (SD)) were compared to the glass control and analyzed using unpaired two-tailed $t$ test.

2.5. Direct Contact with MWCNT-Coated Silicon Wafers. L929 and R28 cells were plated on the wafer slices or on glass at a density of 31,250 cells $/ \mathrm{cm}^{2}$ and 10,000 cells $/ \mathrm{cm}^{2}$, respectively. Cell densities were chosen with regard to the subsequent assay to give evaluable results. After a cultivation time of 72 hours at $37^{\circ} \mathrm{C}$, cell viability was assessed using $5 \mu \mathrm{g} / \mathrm{mL}$ fluorescein diacetate (FDA, Sigma-Aldrich Chemie, Taufkirchen, Germany) and $10 \mu \mathrm{g} / \mathrm{mL}$ propidium iodide (PI, Sigma-Aldrich Chemie) in PBS/0.1\% acetone, which stains live cells green and dead cells red. Immediately after staining, structures were evaluated by fluorescence microscopy in several randomly selected microscopic fields. The total cell numbers were normalized to the respective glass control. The amount of dead cells was calculated as percentage of the corresponding total cell number. Data (mean \pm SD) were compared to the glass control and analyzed using unpaired two-tailed $t$ test.

For scanning electron microscopy (SEM), R28 cells were plated at a density of 10,000 cells $/ \mathrm{cm}^{2}$ and incubated at $37^{\circ} \mathrm{C}$ for 72 hours. After fixation in $3 \%$ glutaraldehyde for 1 hour at room temperature and 4 hours at $4^{\circ} \mathrm{C}$, cells were washed with $0.1 \mathrm{M}$ Sorensen's phosphate buffer for $15 \mathrm{~min}$, followed by dehydration using an increasing series of ethanol concentrations. The samples were coated with $12.5 \mathrm{~nm}$ goldpalladium (Leica EM SCD500; Leica Microsystems, Wetzlar, Germany) and analyzed by SEM (FEI/Philips XL30 ESEMFEG).

2.6. Quantitative Real-Time Polymerase Chain Reaction ( $q R T$ $P C R)$. Expression levels of genes involved in the cell cycle and representing retinal and neuronal/glial markers were analyzed by qRT-PCR. The primer sequences are detailed in 
TABle 1: Primers used in qRT-PCR.

\begin{tabular}{lcc}
\hline GAPDH & Upstream & Sequence $\left(5^{\prime}\right.$ to $\left.3^{\prime}\right)$ \\
\hline \multirow{2}{*}{ HPRT1 } & Downstream & $\begin{array}{c}\text { tgg gaa gct ggt cat caa c } \\
\text { gca tca ccc cat ttg atg tt }\end{array}$ \\
\hline \multirow{2}{*}{ S100B } & Upstream & ctc ctc aga ccg ctt ttc c \\
& Upstream & tca taa cct ggt tca tca tca cta a \\
\hline \multirow{2}{*}{ VIM } & Downstream & cac tgg tcc agg tct ttc att \\
\hline \multirow{2}{*}{ NRP1 } & Upstream & aac act cct gat taa gac ggt tg \\
& Downstream & tca tcg tgg tgc tga gaa gt \\
\hline \multirow{2}{*}{ CDH2 } & Upstream & cat agt ggg ctc gga ctg a \\
& Downstream & ggt cca gct gta ggc act tc \\
\hline \multirow{2}{*}{ UCNC } & Upstream & cca tca tcg cga tac ttc tg \\
& Downstream & cca tac cac gaa cat gag ga \\
\hline \multirow{2}{*}{ MYC } & Upstream & aaa acc acc tcc gaa cag tg \\
& Downstream & gat tgg ctg tag cta gag ttc tga c \\
\hline \multirow{2}{*}{ TP53 } & Upstream & gct cct cgc gtt att tga ag \\
& Downstream & gca tcg tcg tga ctg tcg \\
\hline & Upstream & aga gag cac tgc cca cca \\
& Downstream & aac atc tcg aag cgc tca c \\
\hline
\end{tabular}

Table 1. R28 cells were plated on the wafer slices or on glass at a density of 10,000 cells $/ \mathrm{cm}^{2}$. After a cultivation time of 72 hours at $37^{\circ} \mathrm{C}$, total RNA was isolated using the RNeasy Mini Kit together with the RNase-free DNase Set (Qiagen, Hilden, Germany) according to the protocol of the manufacturer. Reverse transcription was carried out on $20 \mathrm{ng}$ total RNA using the Reverse Transcription System (Promega). Realtime PCR reactions were performed on a LightCycler 1.2 Instrument using the LightCycler FastStart DNA Master SYBR Green I kit (Roche Diagnostics, Mannheim, Germany) according to the manufacturer's recommendations. For quantification of mRNA expression levels, cDNA samples were run in duplicate or triplicate together with the internal control genes GAPDH and HPRT1. Reactions were performed with diluted cDNA, corresponding to $0.4 \mathrm{ng}$ of initially used total RNA, and a primer concentration of $0.1 \mu \mathrm{M}$ and $0.25 \mu \mathrm{M}$, respectively. Thermal cycler conditions were set as follows: initial denaturation at $95^{\circ} \mathrm{C}$ for 10 minutes followed by 50 cycles with denaturation at $95^{\circ} \mathrm{C}$ for 10 seconds, annealing at $60^{\circ} \mathrm{C}$ for 8 seconds, and elongation at $72^{\circ} \mathrm{C}$ for 15 seconds. Melting curve analysis confirmed amplification specificity of each primer pair. Data were processed by LightCycler software 3.5.3 (Roche Diagnostics) and analyzed using the comparative CT $\left(2^{-\Delta \Delta \mathrm{CT}}\right)$ method, which describes relative gene expression [28]. Statistical analysis was performed using one sample two-tailed $t$ test.

Even though analysis of the data revealed a constant expression for both internal control genes, the lowest standard deviation was achieved with GAPDH. Thus, gene expression levels of all target genes were normalized to the GAPDH expression level.

\section{Results}

3.1. Effects of Extractive Media on Cell Survival. For both L929 and R28 cells, incubation with the nontoxic extractive media generated either from the glass substrate or the RM C control exhibited a consistent luminescent output at each applied dilution (Figure 2). Incubation with the nondiluted extractive media generated from the positive RM A and RM B caused a significant reduction of at least $99.9 \%$ in the luminescence values (Figures 2(a) and 2(b)), indicating their cytotoxic effects, which in turn decreased with increasing dilutions (Figures 2(c)-2(f)). Direct comparison of RM A and RM B confirmed that RM B exhibited a weaker cytotoxicity than RM A, especially at the higher dilutions $1: 2$ and 1:4 (Figures 2(c)-2(f)). The data from extractive media of noncoated (blank) and MWCNT-covered silicon wafers were all in the same range as the glass and the RM $\mathrm{C}$ values and thus did not show any evidence of cytotoxicity (Figure 2). One exception was the nondiluted extractive medium of the blank wafer control, which showed a significant decrease of $14.5 \%$ in the luminescence values for L-929 cells (Figure 2(a)). Adhesion and coating of any MWCNT on the silicon substrate was neither affected by sterilization nor by incubation in cell culture medium.

3.2. Effects of Direct Contact with MWCNT Structures on Cell Viability. L-929 cells were able to grow on the noncoated as well as on the MWCNT-covered silicon wafer slices (Figure 3(a)); the total cell number was comparable between the glass and the blank controls but reduced by $4.4 \%$ up to $20.8 \%$ in case of the MWCNT-coated structures, with the lowest total cell number determined for the $\mathrm{Fe}$ Ti generated MWCNT (Figure 3(b)). For all structures, the percentage of dead cells was below 6\% (Figure 3(c)), with the highest amount observed for the MWCNT-Fe wafer slices $(3.1 \pm 2.1 \%)$, followed by MWCNT-Fe-Ti $(2.2 \pm 1.5 \%)$. The amount of dead cells on MWCNT-Fe-Pt $(0.8 \pm 1.1 \%)$ and the noncoated silicon wafers $(1.2 \pm 0.9 \%)$ was slightly lower than on the glass control $(1.5 \pm 1.7 \%)$.

R28 cells showed the highest total cell number when cultivated on glass (Figure 4(a)). The total cell number on all tested wafer slices was reduced, in some cases significantly, by $20.5 \%$ up to $42.6 \%$, with the lowest total cell number detected after cultivation on the MWCNT-Fe-covered and the MWCNT-Fe-Ti-covered silicon wafers (Figure 4(a)). For all tested structures, the percentage of dead cells did not exceed $2 \%$ (Figure $4(\mathrm{~b})$ ). The highest portion of dead cells was determined on the MWCNT-Fe-Ti substrate $(0.8 \pm 0.6 \%)$, which was comparable to the value evaluated after cultivation on glass $(1.0 \pm 0.9 \%)$.

\subsection{Gene Expression Profile of R28 Cells after Cultivation} on MWCNT Structures. In contrast to the cultivation on glass and the noncoated silicon wafers, R28 cells cultivated on MWCNT-Fe and MWCNT-Fe-Pt-covered silicon wafers showed a more separated growth and lacked the morphological characteristic cluster formation (Figure 5(a)). To understand these differences, expression levels of a number of genes essential to the cell cycle and describing neuronal/glial 

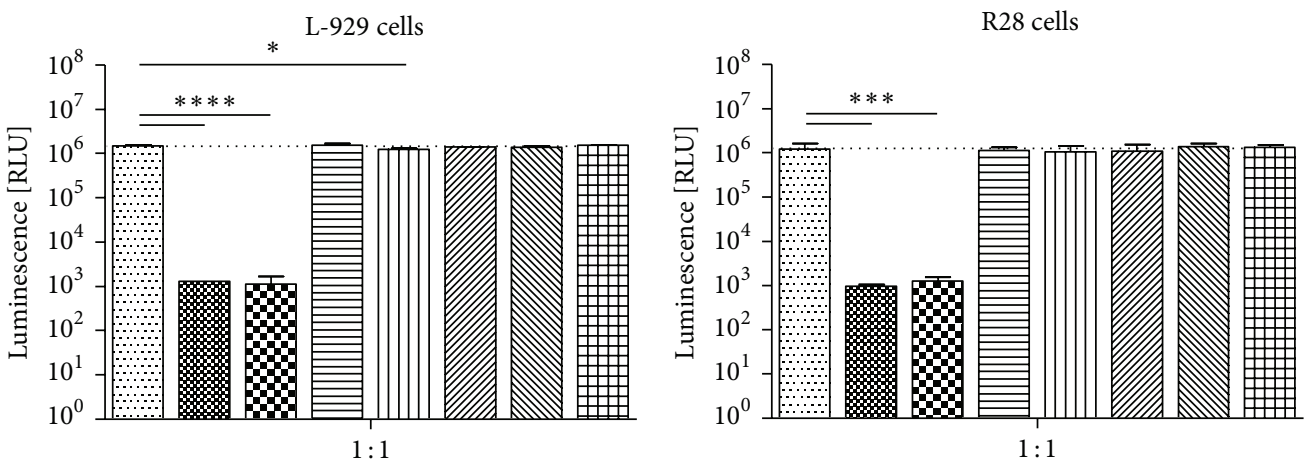

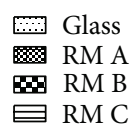

미 Blank שִ MWCNT-Fe MWCNT-Fe-Pt 巴 MWCNT-Fe-Ti

(a)

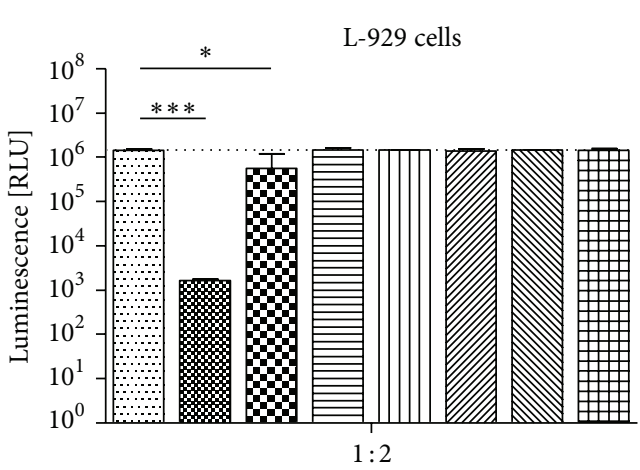

미 Blank שII MWCNT-Fe MWCNT-Fe-Pt 回 MWCNT-Fe-Ti

(c)
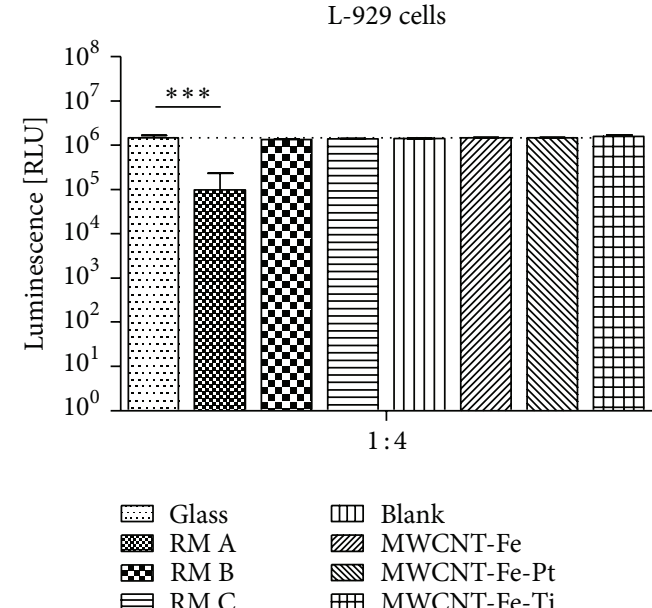

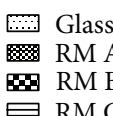

RMC

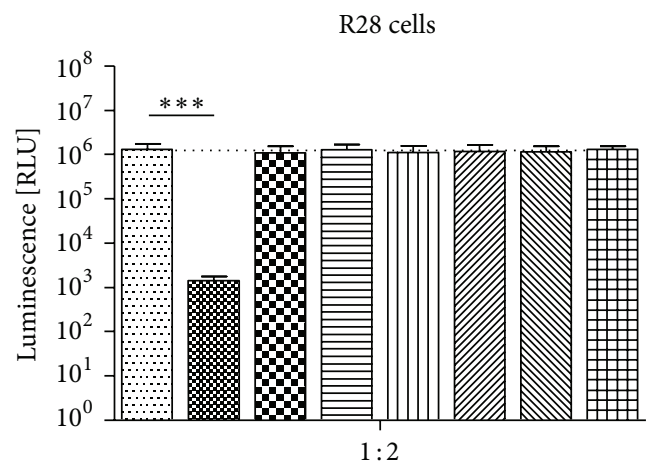

미 Blank UI MWCNT-Fe MWCNT-Fe-Pt 巴MWCNT-Fe-Ti

(b)

$\square$ Glass
RM A
RM B
RM C

س) Blank שדת MWCNT-Fe MWCNT-Fe-P 田 MWCNT-Fe-T

(d)
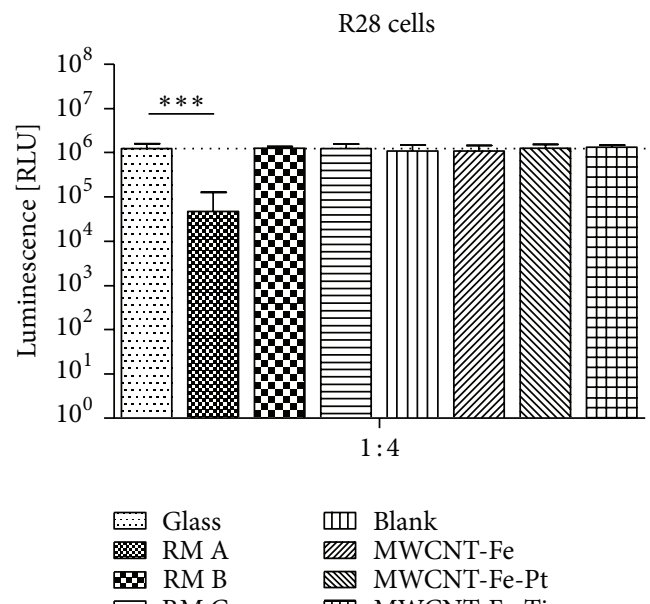

미 Blank

שIת MWCNT-Fe MWCNT-Fe-Pt \# MWCNT-Fe-Ti

(f)

Figure 2: Effects of extractive media on cell survival. Analysis of cell viability in cultures of L-929 cells ( $n=2$ individual experiments) and R28 cells ( $n=4$ individual experiments) incubated for 24 hours with increasing serial dilutions of extractive media obtained from different wafer slices (blank, MWCNT-Fe, MWCNT-Fe-Pt, and MWCNT-Fe-Ti) and certified positive (RM A, RM B) and negative (RM C) reference materials. Extractive medium without the incubation of any material (glass) was used as internal negative control; its mean values are marked by the dotted lines. Data are represented as mean \pm SD. They were compared to the glass control and analyzed using unpaired two-tailed $t$ test. (a) ${ }^{* * * *} P<0.0001$, RM A and RM B; ${ }^{*} P=0.0243$, blank. (b) ${ }^{* * *} P=0.0010$, RM A and RM B. (c) ${ }^{* * *} P=0.0002, \mathrm{RM} \mathrm{A} ;{ }^{*} P=0.0476$, RM B. (d) ${ }^{* * *} P=0.0009$, RM A. (e) ${ }^{* * *} P=0.0007$, RM A. (f) ${ }^{* * *} P=0.0010$, RM A. 


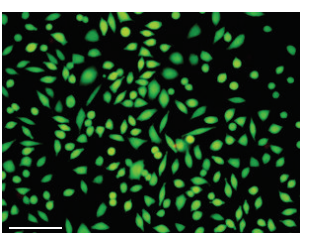

Glass

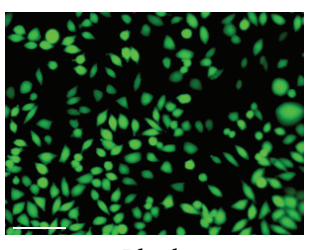

Blank

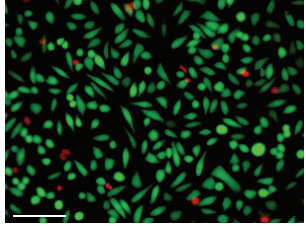

MWCNT-Fe

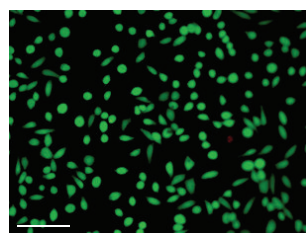

MWCNT-Fe-Pt

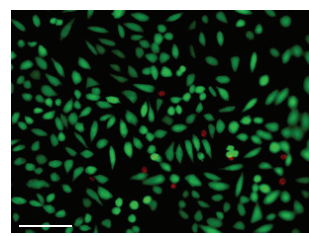

MWCNT-Fe-Ti

(a)

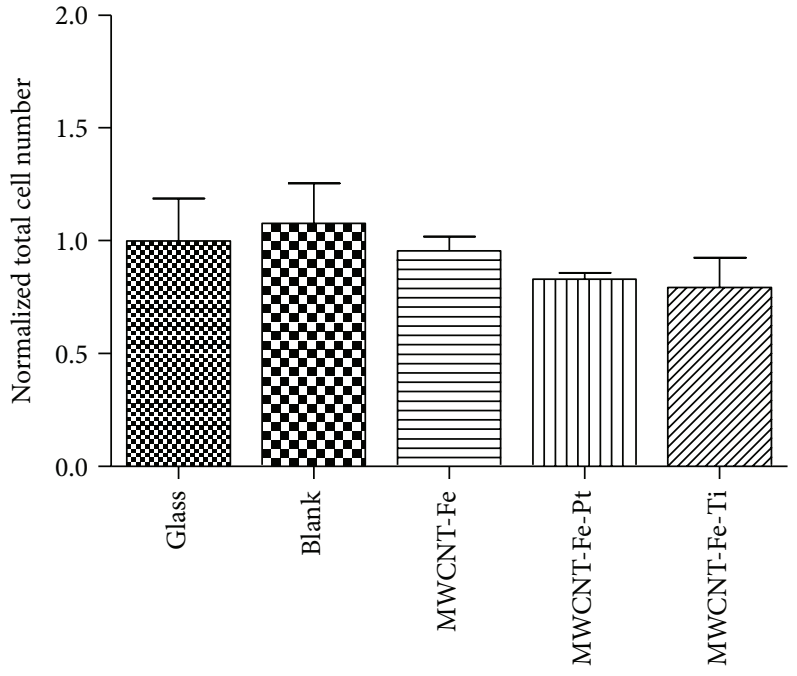

(b)

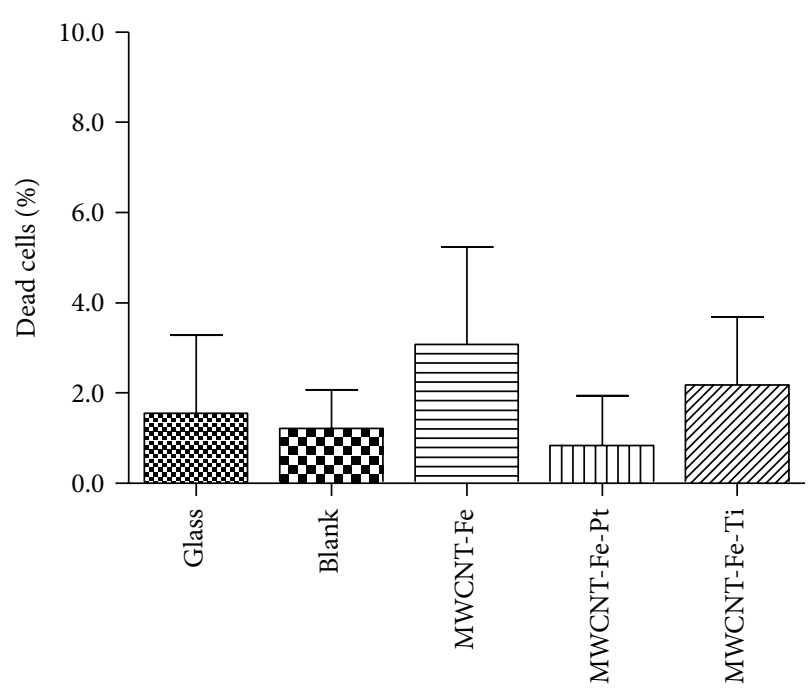

(c)

Figure 3: Effects of direct contact on viability of L-929 cells. Cells were plated on a glass substrate and on the blank, MWCNT-Fe, MWCNTFe-Pt, and MWCNT-Fe-Ti wafer slices ( $n=1$ experiment), stained using FDA/PI, and counted 72 hours after seeding. (a) Fluorescence microscopy allowed for differentiation between vital (green) and dead (red) cells (scale bar: $100 \mu \mathrm{m}$ ). (b) The total cell numbers were normalized to the respective glass control. (c) The quantity of dead cells is shown as a percentage of the corresponding total cell number. For each substrate, 6 randomly selected microscopic fields were analyzed. Data are represented as mean \pm SD. They were compared to the glass control and analyzed using unpaired two-tailed $t$ test, showing no significant differences.

and retinal markers were determined, whereby the values obtained for the cultivation on the wafer pieces were compared to the expression profile evaluated for the cultivation on glass (Figures 5(b)-5(d)).

Compared to the glass control, expression of the retinal cell marker gene $S 100 B$ was not significantly changed in R28 cells cultivated on MWCNT-Fe-Pt silicon wafers (median relative expression ratio: 1.1; Figure 5(d)), while cultivation on noncoated and MWCNT-Fe wafers led to a slight increase (blank: 1.8; Figure 5(b)) and decrease (MWCNT-Fe: 0.5; Figure 5(c)), respectively. The retinal cell marker gene VIM, encoding for the intermediate filament protein vimentin, was significantly downregulated when cultivated on the different wafer slices (blank: 0.2; MWCNT-Fe: 0.3; MWCNT-Fe-Pt: $0.3)$. Its expression was nearly identical to the values observed for the neuronal protein receptor neuropilin (NRP1) (blank: 0.2; MWCNT-Fe: 0.2; MWCNT-Fe-Pt: 0.2). Gene expression of the transmembrane protein $\mathrm{N}$-cadherin $(\mathrm{CDH} 2)$ was also significantly downregulated, to an even higher degree in case of the MWCNT-covered silicon wafers (blank: 0.3; MWCNT-Fe: 0.1; MWCNT-Fe-Pt: 0.1). In cells collected after cultivation on MWCNT-covered probes, expression of cyclin $\mathrm{C}(\mathrm{CCNC})$, a gene that controls nuclear cell division, was decreased to a greater extent than in the noncoated probes (blank: 0.6; MWCNT-Fe: 0.4; MWCNT-Fe-Pt: 0.4). Both the protooncogene MYC (blank: 0.5; MWCNT-Fe: 0.4) and the tumor suppressor gene TP53 (blank: 0.3; MWCNT-Fe: 0.4; MWCNT-Fe-Pt: 0.3) exhibited a significant downregulation in relative gene expression ratio, with exception of the MYC expression in cells cultivated on MWCNT-Fe-Pt silicon wafers (median relative expression ratio: 0.7; Figure 5(d)).

3.4. Growth Characteristics of R28 Cells after Cultivation on Plasma-Treated MWCNT Structures. Cell viability and the gene expression profile on plasma-treated MWCNTFe-Pt were compared to nonfunctionalized MWCNT-Fe-Ptcovered silicon wafers from the same production batch. With regard to the indirect contact, almost no significant cytotoxic effect was observed (Figure 6(a)). Only the nondiluted extract of the plasma-treated MWCNT showed a significant decrease of $36.4 \%$ in the luminescent output (Figure 6(a), left panel). R28 cells showed the highest total cell number when cultivated on glass, which decreased by $11.2 \%$ for the nonfunctionalized MWCNT-Fe-Pt silicon wafers and by $38.2 \%$ for the plasma-treated MWCNT-Fe-Pt silicon wafers (Figure 6(b), left panel). Cultivation on plasma-treated 


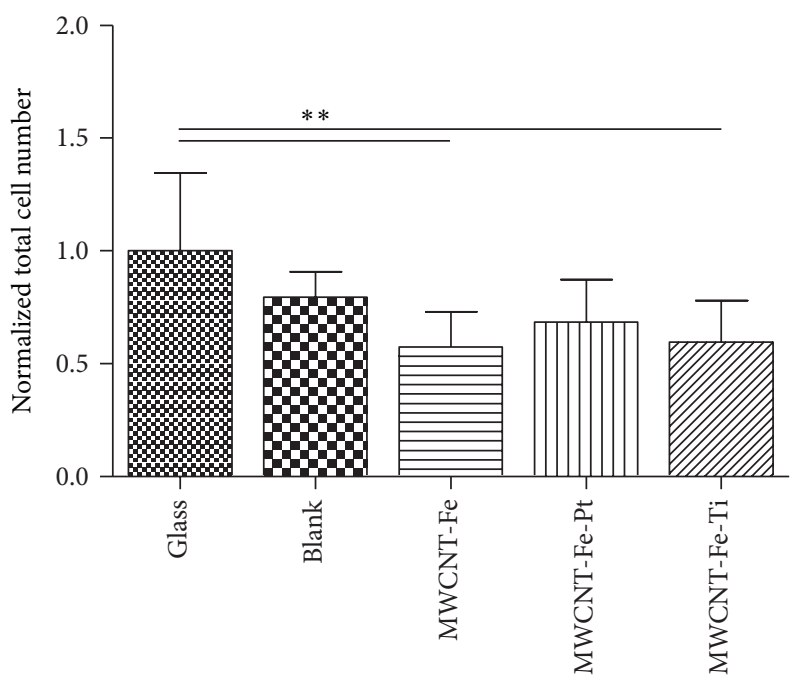

(a)

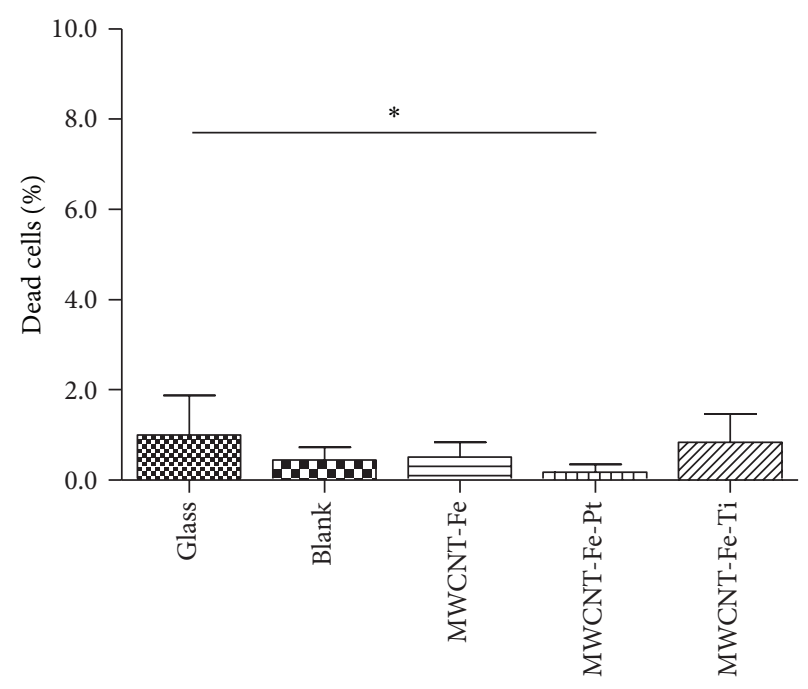

(b)

FIGURE 4: Effects of direct contact on viability of R28 cells. Cells were plated on a glass substrate and on the blank, MWCNT-Fe, MWCNTFe-Pt, and MWCNT-Fe-Ti wafer slices ( $n=2$ individual experiments), stained using FDA/PI, and counted 72 hours after seeding. For each substrate, 8 randomly selected microscopic fields were analyzed. Data are represented as mean \pm SD. They were compared to the glass control and analyzed using unpaired two-tailed $t$ test. (a) The total cell numbers were normalized to the respective glass control. ${ }^{* *} P=0.0077$, MWCNT-Fe; ${ }^{* *} P=0.0093$, MWCNT-Fe-Ti. (b) The quantity of dead cells is shown as a percentage of the corresponding total cell number. ${ }^{*} P=0.0322$, MWCNT-Fe.

MWCNT-Fe-Pt led to a significant increase in the amount of dead cells ( $4.1 \pm 3.4 \%$; Figure $6(\mathrm{~b})$, right panel), when compared to the cultivation on nonfunctionalized MWCNT silicon wafers $(0.6 \pm 0.6 \%)$ and on glass $(0.3 \pm 0.2 \%)$. Regarding gene expression, growth on the plasma-treated MWCNT did not result in any significant changes when compared to the growth on the nonfunctionalized structures (Figure 6(c)). The median relative expression ratios were almost 1.0 for TP53 and $C D H 2$, whereas a slight upregulation was found for the other tested genes (NRP1: 1.2; VIM: 1.5; S100B: 1.7; MYC: 1.7; CCNC: 1.8). R28 cell growth on the nonfunctionalized and the plasma-treated MWCNT-Fe-Pt-covered silicon wafers was also analyzed by SEM (Figure 6(d)), which allowed for the illustration of good cell adhesion and biocompatibility properties.

\section{Discussion}

Platinum and iridium oxide are the most frequently used electrode materials for the stimulation of neural tissue; they were shown to be biocompatible and to provide charge injection amounts suitable to achieve neural excitation [29-31]. Nevertheless, in terms of chronic stimulation their stability is controversially discussed. Both materials can be used in standardized processes to fabricate patterned microelectrode arrays. However, in order to produce smaller electrodes for high density electrode arrays, the charge injection limit will become a critical factor. Consequently, electrode materials that provide charge injection via a small diameter are needed, thus increasing charge injection density, but without yielding toxic effects within the tissue and without inducing electrochemical damage at the electrode surface. Based on the geometry and the surface area of the electrode as well as its distance towards the tissue to be stimulated, Shannon [32] determined a model for safe levels of electrical stimulation. Subsequently, this empiric model was adjusted by in vivo studies of Butterwick et al. [33], who pointed out that for small electrodes, the charge density is not conserved along the strength-duration curve.

Wang et al. [19] showed that vertically aligned MWCNT pillars can be used as microelectrodes for the in vitro stimulation of embryonic rat hippocampal neurons; compared to bare platinum, the MWCNT electrodes offered a 5to 10-fold higher charge injection ability. Even stimulation charge densities up to $40.7 \mathrm{mC} / \mathrm{cm}^{2}$ were reported to be safe [34], suggesting vertically aligned MWCNT grown on microelectrode arrays as a good candidate for the use in neural prostheses. In contrast, safe charge injections of 0.05 up to $5.0 \mathrm{mC} / \mathrm{cm}^{2}$ were described for pure metal electrodes $[29,35]$. In vivo application of CNT-modified electrodes in a mouse brain revealed a more efficient detection of action potentials [36]. The functionality of a CNT-coated microelectrode array was demonstrated by its chronic in vivo implantation into the motor cortex of a cat [37].

The medical application of nanomaterials in implants represents a contentious issue, as their mechanisms of toxicity may differ from microscale particles or larger devices. MWCNT, whose toxicity depend on their physicochemical properties including structure, surface topology, and manufacturing method, can induce membrane and DNA damage as well as changes in cellular processes and metabolic 

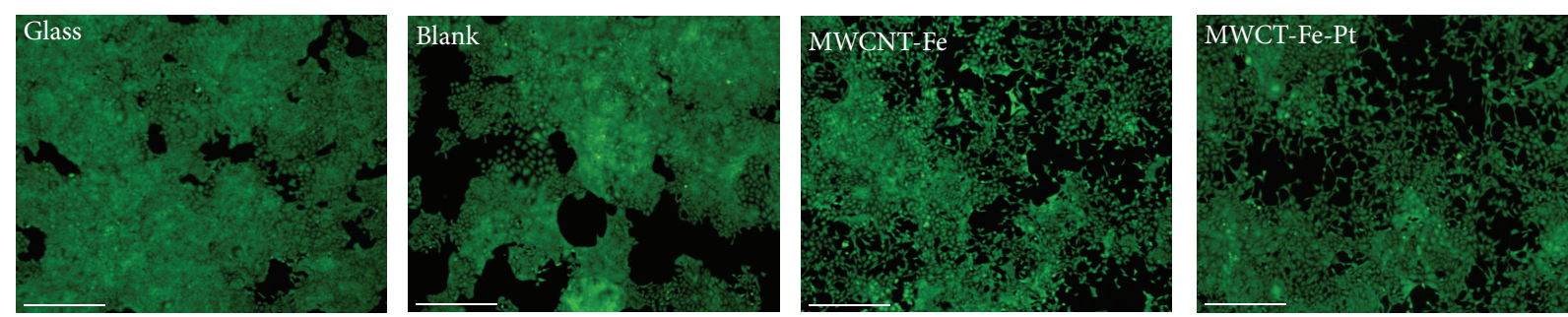

(a)

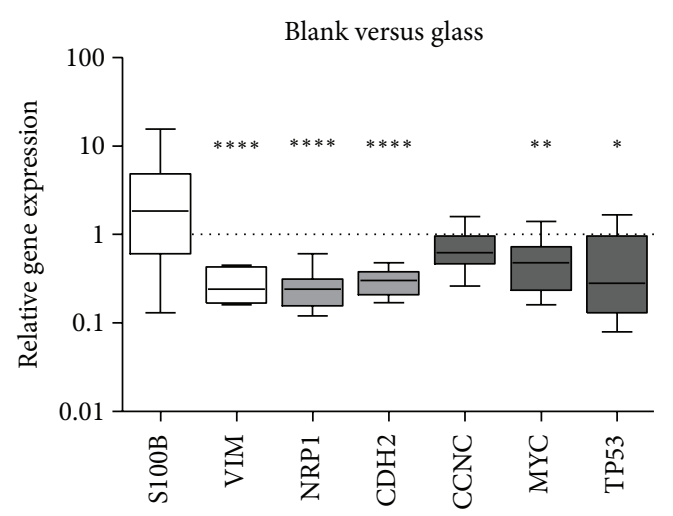

(b)



(c)

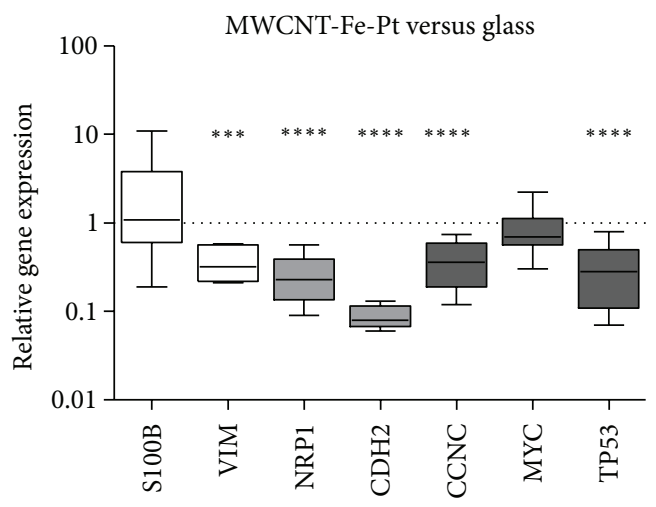

(d)

FIGURE 5: Evaluation of relative gene expression patterns in R28 cells. Cells were plated on a glass substrate and on the blank, MWCNT-Fe, and MWCNT-Fe-Pt wafer slices ( $n=2$ individual experiments). Cultivation was terminated 72 hours after seeding. (a) Fluorescence micrographs showed that R28 cells grown on the MWCNT-Fe and the MWCNT-Fe-Pt wafer slices did not exhibit the characteristic cluster formation as seen on the glass and the blank substrata but showed a lot of separated cells (scale bar: $500 \mu \mathrm{m})$. ((b)-(d)) qRT-PCR was performed to analyze the expression of different genes representing neuronal/glial and retinal markers or involved in the cell cycle. Using the comparative CT $\left(2^{-\Delta \Delta \mathrm{CT}}\right)$ method, the relative gene expression ratio of cells cultivated on glass was set to 1 . Regarding cultivation on the different wafer slices, values $>1$ denote upregulation and values $<1$ denote downregulation of gene expression. Each column represents the median, maximum, minimum, and the 50th percentile of the data. Data were analyzed using one sample two-tailed $t$ test. (b) ${ }^{* * * *} P<0.0001, V I M, N R P 1$, and CDH2; ${ }^{* *} P=0.0072, M Y C ;{ }^{*} P=0.0472$, TP53. (c) ${ }^{* * *} P=0.0002, V I M ;{ }^{* * * *} P<0.0001, N R P 1, C D H 2$, and $C C N C ;{ }^{* * *} P=0.0003, M Y C$; ${ }^{*} P=0.0278, T P 53$. (d) ${ }^{* * *} P=0.0002$, VIM; ${ }^{* * * *} P<0.0001, N R P 1, C D H 2, C C N C$, and TP53.

pathways [38, 39]. However, it is important to distinguish between MWCNT applied as coating on a substrate and their dispersion in a liquid environment. Gladwin et al. [40] showed that medium conditioned with MWCNT was not significantly toxic, whereas MWCNT dispersed in cell culture medium led to a reduction in cell viability. Concerning our final intention of coating a stable MWCNT layer on an electrode array, we only investigated the cytotoxic effects of MWCNT conditioned medium. Additionally, as implanted
MWCNT-covered microelectrode structures would get in contact with the remaining cells of the neural tissue of patients, we seeded cells directly onto the different MWCNTcoated silicon wafers. Neither the extractive media nor the direct cell contact caused a significant decrease in cell viability, indicating that no cytotoxic substance was released during incubation of the MWCNT-covered wafer slices in a liquid environment. The ratio of dead cells did not exceed $2 \%$ for R28 cells and 6\% for L-929 cells. According to part 5 of the 

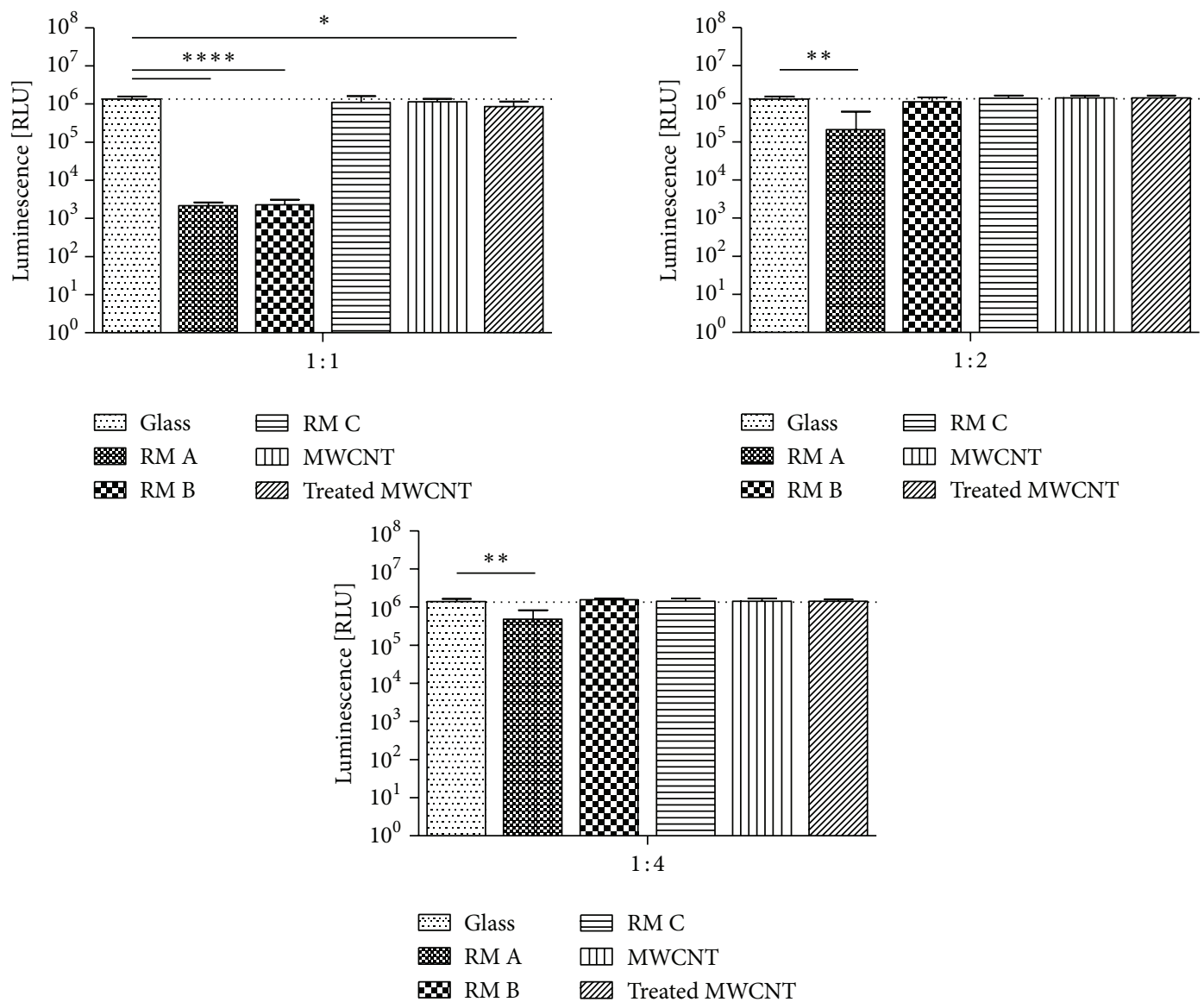

(a)
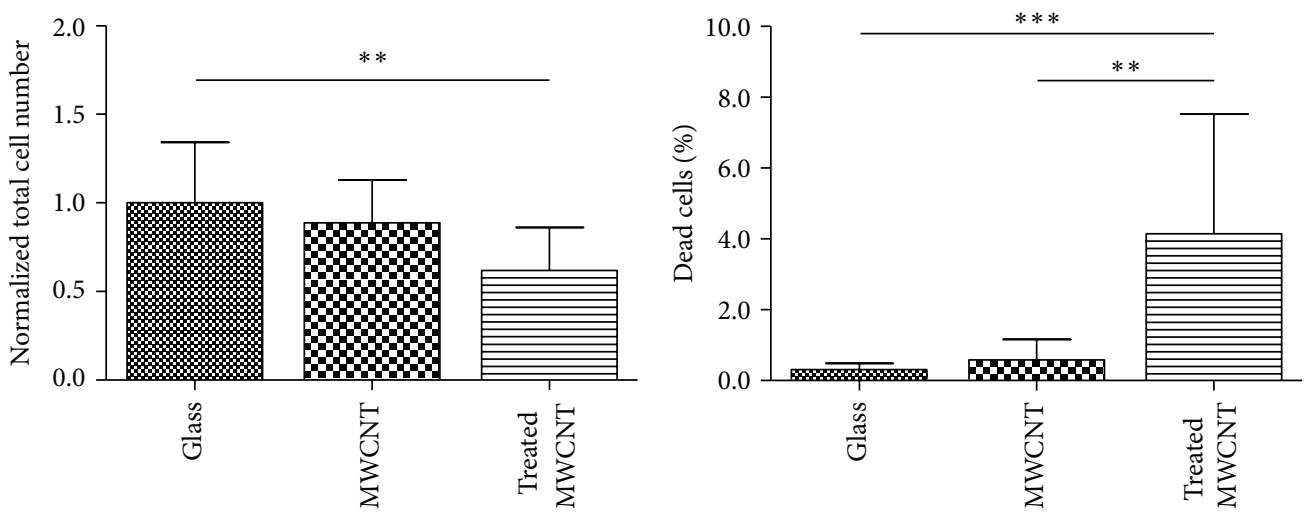

(b)

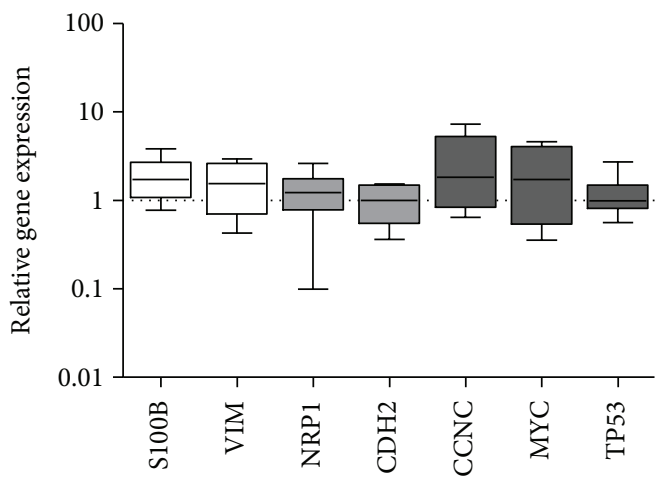

(c)

FIGURE 6: Continued. 

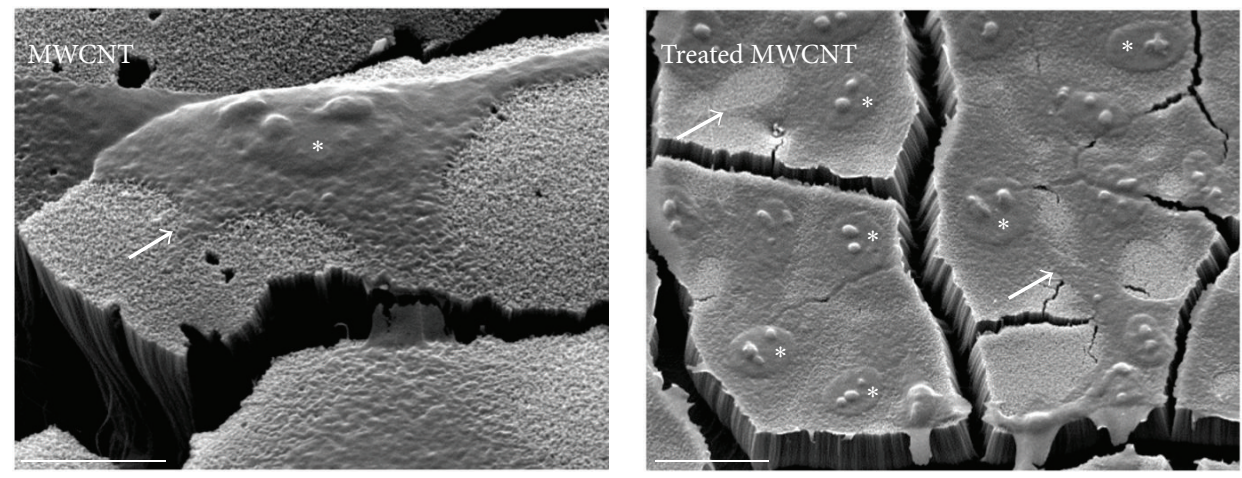

(d)

FIGURE 6: Growth characteristics of R28 cells after cultivation on plasma-treated MWCNT structures. (a) Analysis of cell viability in cultures incubated for 24 hours with increasing serial dilutions of extractive media obtained from nonfunctionalized and plasma-treated MWCNTFe-Pt wafer slices and certified RM A, RM B, and RM C ( $n=4$ individual experiments). Extractive medium without the incubation of any material (glass) was used as internal negative control; its mean values are marked by the dotted lines. Data are represented as mean \pm SD. They were compared to the glass control and analyzed using unpaired two-tailed $t$ test. ${ }^{* * * *} P<0.0001, \mathrm{RM} \mathrm{A}(1: 1)$ and RM B (1:1); ${ }^{*} P=0.0319$, treated MWCNT $(1: 1) ;{ }^{* *} P=0.0037$, RM A $(1: 2) ;{ }^{* *} P=0.0047$, RM A $(1: 4)$. (b) Effects of direct contact on viability of cells grown on glass and on nonfunctionalized and plasma-treated MWCNT-Fe-Pt wafer slices ( $n=3$ individual experiments). Cells were stained using FDA/PI and counted 72 hours after seeding. For each substrate, 12 randomly selected microscopic fields were analyzed. Data are represented as mean \pm SD. The total cell numbers were normalized and compared to the glass control and analyzed using unpaired two-tailed $t$ test $\left({ }^{* *} P=0.0048\right.$, treated MWCNT). The quantity of dead cells is shown as a percentage of the corresponding total cell number. They were compared to the treated MWCNT probe and analyzed using unpaired two-tailed $t$ test $\left({ }^{* * *} P=0.0007\right.$, glass; $\left.{ }^{* *} P=0.0016, \mathrm{MWCNT}\right)$. (c) qRT-PCR was used to analyze the expression of different genes representing neuronal/glial and retinal markers or involved in the cell cycle $\left(n=3\right.$ individual experiments). Using the comparative CT $\left(2^{-\Delta \Delta \mathrm{CT}}\right)$ method, the relative gene expression ratio of cells cultivated on nonfunctionalized MWCNT was set to 1 . For plasma-treated MWCNT, values $>1$ denote an upregulated and values $<1$ denote a downregulated gene expression. Each column represents the median, maximum, minimum, and the 50th percentile of the data. Data were analyzed using one sample two-tailed $t$ test, showing no significant differences. (d) Scanning electron microscopy images of R28 cells plated on nonfunctionalized (scale bar: $10 \mu \mathrm{m}$ ) and plasma-treated (scale bar: $20 \mu \mathrm{m}$ ) MWCNT-Fe-Pt silicon wafers. Cultivation was terminated 72 hours after seeding. Arrows indicate cell adhesion and individual cell nuclei are marked with stars. Note that the cracks within the MWCNT structures were due to the fixation and drying processes.

standard ISO 10993, a reduction in cell viability of more than $30 \%$ is defined as cytotoxic.

Li et al. [41] published a microRNA expression-based method to assess the cytotoxic effect of nanomaterials. In NIH/3T3 cell culture experiments, they showed that MWCNT had less effect on cell survival and cellular morphology than the simultaneous tested nanoparticles and quantum dots, which both were much smaller in size. MWCNT were also found to affect regulation of the $\mathrm{NIH} / 3 \mathrm{~T} 3$ fibroblast actin cytoskeleton, which corresponded to previously published data that described the effects of carbon nanotubes on human aortic endothelial cells [42]. However, the use of carbon nanotubes together with poly(ethylenedioxythiophene) (PEDOT) for the coating of platinum electrodes implanted into the rat brain exhibited a positive effect compared to bare platinum electrodes in terms of histological changes with less inflammation surrounding the electrodes [43].

Our cell culture experiments revealed that after direct contact with the respective MWCNT, R28 cells showed a more separated growth with a morphologically reduced cluster formation, whereas the growth pattern of L-929 cells was not affected. Accordingly, the decrease of the total cell number was more apparent in cultures of R28 cells. However, this reduced cell survival ratio was in contrast to the results of Tilton et al. [44], who postulated a MWCNT-dependent regulation of pathways that increase cell proliferation. In turn, Bobrinetskii et al. [45] showed a decreased proliferative activity of human embryo fibroblast and glioblastoma cells cultivated on various types of carbon nanotubes. R28 gene expression analysis revealed an increased downregulation in $\mathrm{CDH} 2$ expression after cultivation on MWCNT-covered silicon wafer slices, which may be an explanation for the reduced cell growth. $\mathrm{CDH} 2$ encodes a calcium-dependent cell adhesion molecule and plays an important role in the formation and maturation of synapses in immature neurons [46]. Additionally, expression of CCNC and MYC was slightly decreased in R28 cells cultured on noncoated and MWCNTcoated silicon wafers, which was consistent with the findings of Liu et al. [47], who described a functional cooperation between CCNC and MYC to induce cell proliferation.

The more separated R28 cell growth may also be explained by the rather hydrophobic property of the MWCNT surface. In fact, we observed slight water repellence effects when the MWCNT-coated wafer slices were incubated in cell culture medium and suggested that a downstream plasma treatment in an oxygen-argon atmosphere could increase the hydrophilicity of the MWCNT surface and thus improve cell adhesion and cell growth. However, compared to nonfunctionalized MWCNT structures, gene expression 
was almost not affected, whereas the total cell number significantly declined and the percentage of dead cells significantly increased. Nevertheless, more than $95 \%$ of the cells were vital.

Our study demonstrated that the analyzed MWCNT fabricated with different catalytic agents were biocompatible for L-929 cells as an ISO 10993 standard biological test system. Although the L-929 cell line is described to be sensitive for cytotoxicity testing, its fibroblastic morphology does not reflect the properties of the retina, which is the target tissue that will ultimately connect with a retinal implantembedded MWCNT-coated electrode array. Beside the loss of the sensory retina, retinal degenerations are characterized by a downstream remodeling of the neural retina, where Müller cells increase the synthesis of intermediate filaments, forming a dense layer in the subretinal space [48]. R28 cells are known to express the glial marker genes $S 100 B$ and VIM [49], whose expression is ubiquitously found in Müller cells [50, 51]. Regarding this, R28 cells are in better agreement with the genetic characteristics of a remodeled neural retina. The results showed that the tested MWCNT were biocompatible for R28 cells, albeit to a slightly reduced extent, because of minor changes in the growth pattern and gene expression.

However, the cell lines only give a first indication of the biocompatibility of the various MWCNT themselves and allow the assumption that implantation of a MWCNTcoated microelectrode array would not lead to immunogenic rejections. The production of MWCNT-functionalized microelectrode arrays is a matter of ongoing research. Future experiments will comprise organotypic cultures of retinas with induced photoreceptor degeneration $[52,53]$ as well as the in vivo implantation in an animal model of retinal degeneration. The studies will also involve the biocompatibility testing of MWCNT-coated microelectrode arrays after application of stimulation pulses, in order to exclude a possible leaching of the $\mathrm{Fe}, \mathrm{Fe}-\mathrm{Pt}$, or Fe-Ti catalysts.

Despite the negligible differences in the biocompatibility, which were not as evident as one would expect from cytotoxic materials, MWCNT-covered microelectrode arrays provide a promising approach to electrically stimulate remaining neural cells in patients with neurodegenerative diseases.

\section{Conclusions}

Different Fe catalyst mixtures were tested to improve the synthesis of vertically aligned MWCNT on silicon wafers. All tested MWCNT-covered slices showed good biocompatibility profiles; as for the direct contact, the amount of dead cells was only one-fifth to one-fifteenth of those what is defined as cytotoxic. Thus, this technology is considered as a promising tool to further improve microelectrode array systems developed to connect with remaining retinal cells. Our results justify continuing the biocompatibility and efficacy testing in vivo in a rabbit model, where the surgical techniques and following treatments are well established in our department.

\section{Competing Interests}

The authors declare that there are no competing interests regarding the publication of this paper.

\section{Acknowledgments}

This work was supported by the Federal Ministry of Education and Research (BMBF) Grant 16SV5322 K. The authors thank Claudia Werner (Department of Ophthalmology, RWTH Aachen University, Aachen, Germany) for excellent technical support.

\section{References}

[1] T. Lenarz, H.-W. Pau, and G. Paasche, "Cochlear implants," Current Pharmaceutical Biotechnology, vol. 14, no. 1, pp. 112-123, 2013.

[2] C.-H. Sung and J.-Z. Chuang, "The cell biology of vision," Journal of Cell Biology, vol. 190, no. 6, pp. 953-963, 2010.

[3] S. P. Daiger, S. J. Bowne, and L. S. Sullivan, "Perspective on genes and mutations causing retinitis pigmentosa," Archives of Ophthalmology, vol. 125, no. 2, pp. 151-158, 2007.

[4] A. F. Wright, C. F. Chakarova, M. M. Abd El-Aziz, and S. S. Bhattacharya, "Photoreceptor degeneration: genetic and mechanistic dissection of a complex trait," Nature Reviews Genetics, vol. 11, no. 4, pp. 273-284, 2010.

[5] K. Stingl, K. U. Bartz-Schmidt, D. Besch et al., "Artificial vision with wirelessly powered subretinal electronic implant alphaIMS," Proceedings of the Royal Society B, vol. 280, no. 1757, Article ID 20130077, 2013.

[6] R. Wilke, V.-P. Gabel, H. Sachs et al., "Spatial resolution and perception of patterns mediated by a subretinal 16-electrode array in patients blinded by hereditary retinal dystrophies," Investigative Ophthalmology and Visual Science, vol. 52, no. 8, pp. 5995-6003, 2011.

[7] L. N. Ayton, P. J. Blamey, R. H. Guymer et al., "First-in-human trial of a novel suprachoroidal retinal prosthesis," PLOS ONE, vol. 9, no. 12, Article ID e115239, 2014.

[8] T. Fujikado, M. Kamei, H. Sakaguchi et al., "Testing of semichronically implanted retinal prosthesis by suprachoroidaltransretinal stimulation in patients with retinitis pigmentosa," Investigative Ophthalmology and Visual Science, vol. 52, no. 7, pp. 4726-4733, 2011.

[9] L. Da Cruz, B. F. Coley, J. Dorn et al., "The Argus II epiretinal prosthesis system allows letter and word reading and long-term function in patients with profound vision loss," British Journal of Ophthalmology, vol. 97, no. 5, pp. 632-636, 2013.

[10] J. Menzel-Severing, T. Laube, C. Brockmann et al., "Implantation and explantation of an active epiretinal visual prosthesis: 2-year follow-up data from the EPIRET3 prospective clinical trial," Eye, vol. 26, no. 4, pp. 501-509, 2012.

[11] G. Roessler, T. Laube, C. Brockmann et al., "Implantation and explantation of a wireless epiretinal retina implant device: observations during the EPIRET3 prospective clinical trial," Investigative Ophthalmology and Visual Science, vol. 50, no. 6, pp. 3003-3008, 2009.

[12] F. Waschkowski, S. Hesse, A. C. Rieck et al., "Development of very large electrode arrays for epiretinal stimulation (VLARS)," BioMedical Engineering Online, vol. 13, no. 1, article 11, 2014.

[13] N. Winkin and W. Mokwa, "Flexible multi-electrode array with integrated bendable CMOS-chip for implantable systems," in Proceedings of the Annual International Conference of the IEEE Engineering in Medicine and Biology Society (EMBC '12), pp. 3882-3885, San Diego, Calif, USA, August 2012. 
[14] S. F. Cogan, A. A. Guzelian, W. F. Agnew, T. G. H. Yuen, and D. B. McCreery, "Over-pulsing degrades activated iridium oxide films used for intracortical neural stimulation," Journal of Neuroscience Methods, vol. 137, no. 2, pp. 141-150, 2004.

[15] D. Harnack, C. Winter, W. Meissner, T. Reum, A. Kupsch, and R. Morgenstern, "The effects of electrode material, charge density and stimulation duration on the safety of high-frequency stimulation of the subthalamic nucleus in rats," Journal of Neuroscience Methods, vol. 138, no. 1-2, pp. 207-216, 2004.

[16] D. B. McCreery, W. F. Agnew, T. G. H. Yuen, and L. Bullara, "Charge density and charge per phase as cofactors in neural injury induced by electrical stimulation," IEEE Transactions on Biomedical Engineering, vol. 37, no. 10, pp. 996-1001, 1990.

[17] P. Stice, A. Gilletti, A. Panitch, and J. Muthuswamy, "Thin microelectrodes reduce GFAP expression in the implant site in rodent somatosensory cortex," Journal of Neural Engineering, vol. 4, no. 2, pp. 42-53, 2007.

[18] S. Minnikanti, M. G. A. G. Pereira, S. Jaraiedi et al., "In vivo electrochemical characterization and inflammatory response of multiwalled carbon nanotube-based electrodes in rat hippocampus," Journal of Neural Engineering, vol. 7, no. 1, Article ID 016002, 2010.

[19] K. Wang, H. A. Fishman, H. Dai, and J. S. Harris, "Neural stimulation with a carbon nanotube microelectrode array," Nano Letters, vol. 6, no. 9, pp. 2043-2048, 2006.

[20] G. Cellot, F. M. Toma, Z. K. Varley et al., "Carbon nanotube scaffolds tune synaptic strength in cultured neural circuits: novel frontiers in nanomaterial-tissue interactions," Journal of Neuroscience, vol. 31, no. 36, pp. 12945-12953, 2011.

[21] G.-Z. Jin, M. Kim, U. S. Shin, and H.-W. Kim, "Neurite outgrowth of dorsal root ganglia neurons is enhanced on aligned nanofibrous biopolymer scaffold with carbon nanotube coating," Neuroscience Letters, vol. 501, no. 1, pp. 10-14, 2011.

[22] V. Lovat, D. Pantarotto, L. Lagostena et al., "Carbon nanotube substrates boost neuronal electrical signaling," Nano Letters, vol. 5, no. 6, pp. 1107-1110, 2005.

[23] A. I. Aria and M. Gharib, "Dry oxidation and vacuum annealing treatments for tuning the wetting properties of carbon nanotube arrays," Journal of Visualized Experiments, no. 74, Article ID 50378, 2013.

[24] M. Gołda, M. Brzychczy-Włoch, M. Faryna, K. Engvall, and A. Kotarba, "Oxygen plasma functionalization of parylene C coating for implants surface: nanotopography and active sites for drug anchoring," Materials Science and Engineering $C$, vol. 33, no. 7, pp. 4221-4227, 2013.

[25] J.-C. Park, B. J. Park, D. H. Lee, H. Suh, D.-G. Kim, and O.H. Kwon, "Evaluation of the cytotoxicity of polyetherurethane (PU) film containing zinc diethyldithiocarbamate (ZDEC) on various cell lines," Yonsei Medical Journal, vol. 43, no. 4, pp. 518526, 2002.

[26] G. M. Seigel, W. Sun, J. Wang, D. H. Hershberger, L. M. Campbell, and R. J. Salvi, "Neuronal gene expression and function in the growth-stimulated R28 retinal precursor cell line," Current Eye Research, vol. 28, no. 4, pp. 257-269, 2004.

[27] G. M. Seigel, "Establishment of an E1A-immortalized retinal cell culture," In Vitro Cellular \& Developmental Biology-Animal, vol. 32, no. 2, pp. 66-68, 1996.

[28] T. D. Schmittgen and K. J. Livak, "Analyzing real-time PCR data by the comparative CT method," Nature Protocols, vol. 3, no. 6, pp. 1101-1108, 2008.
[29] S. F. Cogan, "Neural stimulation and recording electrodes," Annual Review of Biomedical Engineering, vol. 10, pp. 275-309, 2008.

[30] E. S. Ereifej, S. Khan, G. Newaz, J. Zhang, G. W. Auner, and P. J. Vandevord, "Comparative assessment of iridium oxide and platinum alloy wires using an in vitro glial scar assay," Biomedical Microdevices, vol. 15, no. 6, pp. 917-924, 2013.

[31] S. Thanawala, O. Palyvoda, D. G. Georgiev et al., "A neural cell culture study on thin film electrode materials," Journal of Materials Science: Materials in Medicine, vol. 18, no. 9, pp. 17451752, 2007.

[32] R. V. Shannon, "A model of safe levels for electrical stimulation," IEEE Transactions on Biomedical Engineering, vol. 39, no. 4, pp. 424-426, 1992.

[33] A. Butterwick, A. Vankov, P. Huie, Y. Freyvert, and D. Palanker, "Tissue damage by pulsed electrical stimulation," IEEE Transactions on Biomedical Engineering, vol. 54, no. 12, pp. 2261-2267, 2007.

[34] S. Musa, D. R. Rand, D. J. Cott et al., "Bottom-up $\mathrm{SiO}_{2}$ embedded carbon nanotube electrodes with superior performance for integration in implantable neural microsystems," ACS Nano, vol. 6, no. 6, pp. 4615-4628, 2012.

[35] M. Patan, T. Shah, and M. Sahin, "Charge injection capacity of TiN electrodes for an extended voltage range," Engineering in Medicine and Biology Society, vol. 1, pp. 890-892, 2006.

[36] J. H. Shin, G. B. Kim, E. J. Lee et al., "Carbon-nanotubemodified electrodes for highly efficient acute neural recording," Advanced Healthcare Materials, vol. 3, no. 2, pp. 245-252, 2014.

[37] R. A. Parker, S. Negi, T. Davis et al., "The use of a novel carbon nanotube coated microelectrode array for chronic intracortical recording and microstimulation," Engineering in Medicine and Biology Society, vol. 2012, pp. 791-794, 2012.

[38] P. Nymark, P. Wijshoff, R. Cavill et al., "Extensive temporal transcriptome and microRNA analyses identify molecular mechanisms underlying mitochondrial dysfunction induced by multiwalled carbon nanotubes in human lung cells," Nanotoxicology, vol. 9, no. 5, pp. 624-635, 2015.

[39] S. Vardharajula, S. Z. Ali, P. M. Tiwari et al., "Functionalized carbon nanotubes: biomedical applications," International Journal of Nanomedicine, vol. 7, pp. 5361-5374, 2012.

[40] K. M. Gladwin, R. L. D. Whitby, S. V. Mikhalovsky, P. Tomlins, and J. Adu, "In vitro biocompatibility of multiwalled carbon nanotubes with sensory neurons," Advanced Healthcare Materials, vol. 2, no. 5, pp. 728-735, 2013.

[41] S. Li, H. Wang, Y. Qi et al., "Assessment of nanomaterial cytotoxicity with SOLiD sequencing-based microRNA expression profiling," Biomaterials, vol. 32, no. 34, pp. 9021-9030, 2011.

[42] V. G. Walker, Z. Li, T. Hulderman, D. Schwegler-Berry, M. L. Kashon, and P. P. Simeonova, "Potential in vitro effects of carbon nanotubes on human aortic endothelial cells," Toxicology and Applied Pharmacology, vol. 236, no. 3, pp. 319-328, 2009.

[43] X. Cheng, C. Li, L. Rao, H. Zhou, T. Li, and Y. Duan, "Platinum wire implants coated with PEDOT/carbon nanotube conducting polymer films in the brain of rats: a histological evaluation," Journal Wuhan University of Technology, vol. 27, no. 6, pp. 1053-1057, 2012.

[44] S. C. Tilton, N. J. Karin, A. Tolic et al., “Three human cell types respond to multi-walled carbon nanotubes and titanium dioxide nanobelts with cell-specific transcriptomic and proteomic expression patterns," Nanotoxicology, vol. 8, no. 5, pp. 533-548, 2014. 
[45] I. I. Bobrinetskii, R. A. Morozov, A. S. Seleznev, R. Y. Podchernyaeva, and O. A. Lopatina, "Proliferative activity and viability of fibroblast and glioblastoma cell on various types of carbon nanotubes," Bulletin of Experimental Biology and Medicine, vol. 153, no. 2, pp. 259-262, 2012.

[46] K. N. Pielarski, B. van Stegen, A. Andreyeva et al., "Asymmetric $\mathrm{N}$-cadherin expression results in synapse dysfunction, synapse elimination, and axon retraction in cultured mouse neurons," PLoS ONE, vol. 8, no. 1, Article ID e54105, 2013.

[47] Z.-J. Liu, T. Ueda, T. Miyazaki et al., "A critical role for cyclin $\mathrm{C}$ in promotion of the hematopoietic cell cycle by cooperation with c-Myc," Molecular and Cellular Biology, vol. 18, no. 6, pp. 3445-3454, 1998.

[48] R. E. Marc, B. W. Jones, C. B. Watt, and E. Strettoi, "Neural remodeling in retinal degeneration," Progress in Retinal and Eye Research, vol. 22, no. 5, pp. 607-655, 2003.

[49] G. M. Seigel, A. L. Mutchler, and E. L. Imperato, "Expression of glial markers in a retinal precursor cell line," Molecular Vision, vol. 2, article 2, 1996.

[50] D. Cocchia, J. M. Polak, G. Terenghi et al., "Localization of S-100 protein in Müller cells of the retina-2. Electron microscopical immunocytochemistry," Investigative Ophthalmology \& Visual Science, vol. 24, no. 7, pp. 980-984, 1983.

[51] F. Ghosh, "Müller cells in long-term full-thickness retinal transplants," Glia, vol. 37, no. 1, pp. 76-82, 2002.

[52] S. Kaempf, P. Walter, A. K. Salz, and G. Thumann, "Novel organotypic culture model of adult mammalian neurosensory retina in co-culture with retinal pigment epithelium," Journal of Neuroscience Methods, vol. 173, no. 1, pp. 47-58, 2008.

[53] S. Rösch, S. Johnen, A. Mataruga, F. Müller, C. Pfarrer, and P. Walter, "Selective photoreceptor degeneration by intravitreal injection of N-methyl-N-nitrosourea," Investigative Ophthalmology and Visual Science, vol. 55, no. 3, pp. 1711-1723, 2014. 


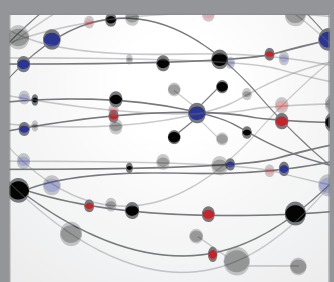

The Scientific World Journal
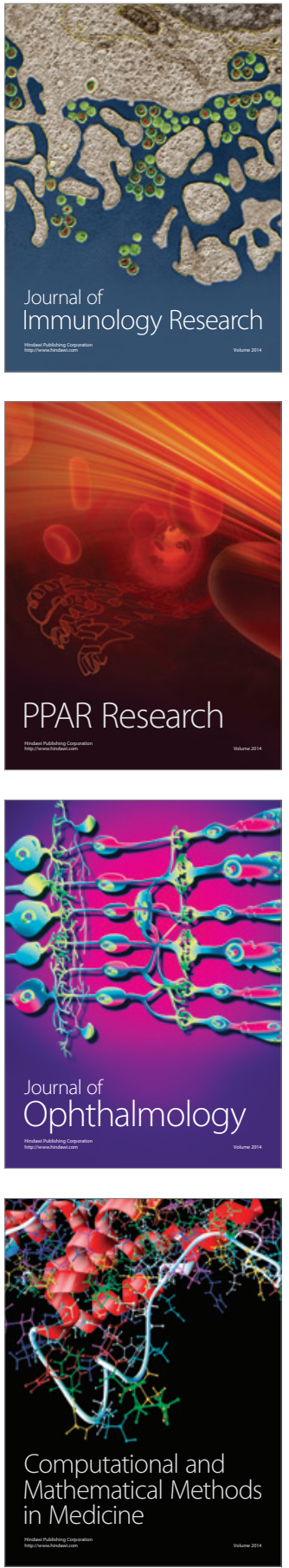

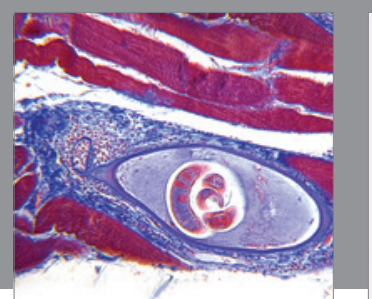

Gastroenterology Research and Practice

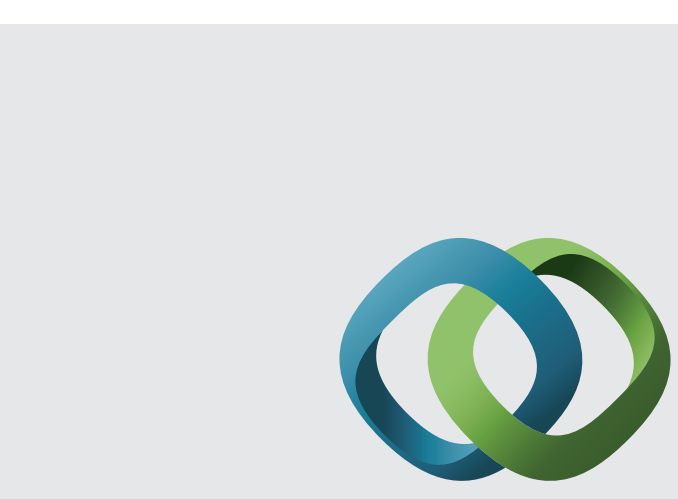

\section{Hindawi}

Submit your manuscripts at

http://www.hindawi.com
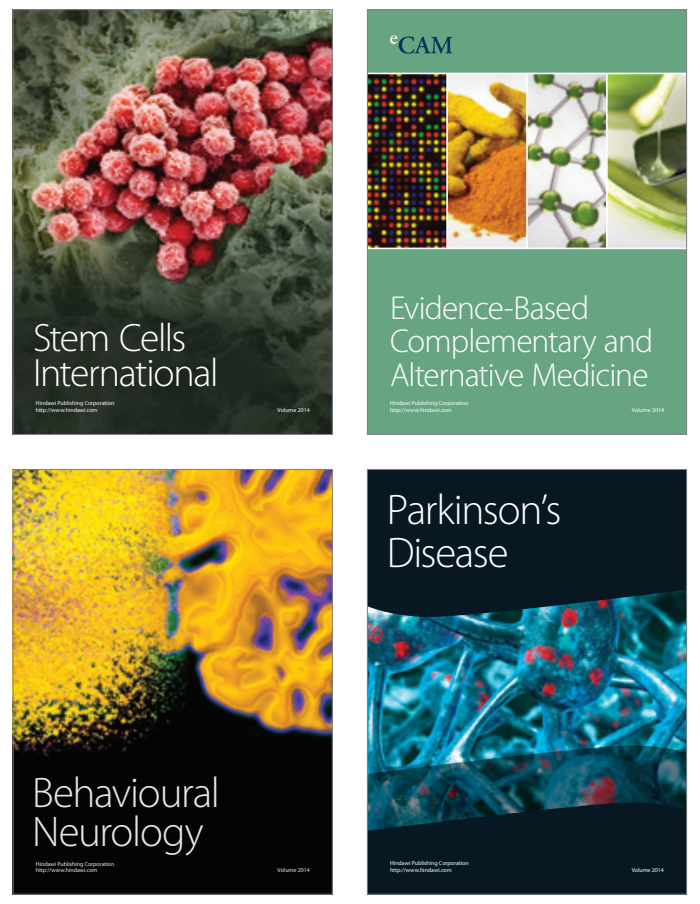


Disease Markers
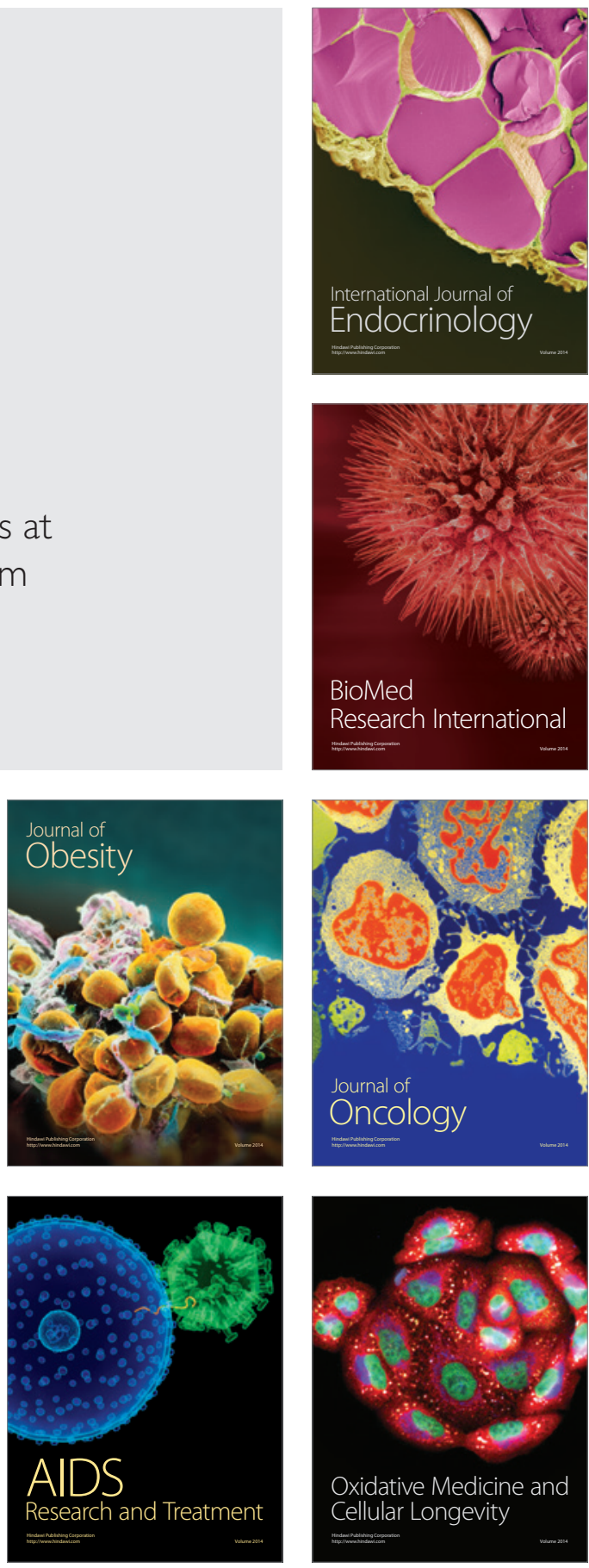